\title{
TeachPsychScience.org: Sharing to Improve the Teaching of Research Methods
}

\author{
David B. Strohmetz ${ }^{*}$ Natalie J. Ciarocco and \\ Gary W. Lewandowski, Jr. \\ Monmouth University \\ *dstrohme@monmouth.edu
}

\section{Editors' Commentary}

Designing a course to be engaging can be challenging, especially when the course in question is one that students often dread having to take and traditional sources of inspiration are limited, static, uneven in quality, or cost-prohibitive. In this chapter, authors David Strohmetz, Natalie Ciarocco, and Gary Lewandowski discuss the development of a website devoted to the sharing of openly-licensed and peer-reviewed strategies and demonstrations for teaching research methods and statistics. In doing so they demonstrate how individual faculty can marry the recognized resources and practices of their discipline, such as support from professional societies and peer review, with open licensing to be able to 'take a little piece of their world and improve it.'

Teaching research methods and statistics can be frustrating. The courses that are foundational to the undergraduate major, and psychological science in general, are the very ones that students often dread or avoid taking. ${ }^{1}$ Even when they do take these classes, they do not necessarily see the value of this newly gained knowledge. ${ }^{2}$ Hence, faculty teaching research methods or statistics in

\section{How to cite this book chapter:}

Strohmetz, D B, Ciarocco, N J, and Lewandowski, Jr. G W. 2017. TeachPsychScience. org: Sharing to Improve the Teaching of Research Methods. In: Jhangiani, R S and Biswas-Diener, R. (eds.) Open: The Philosophy and Practices that are Revolutionizing Education and Science. Pp. 237-244. London: Ubiquity Press. DOI: https://doi.org/10.5334/bbc.s. License: CC-BY 4.0 
psychology often start every semester with a class full of less than enthusiastic students. This attitude does not seem to impede their learning. Most students achieve a baseline mastery of the material, but still leave the class with poor attitudes about statistics and research, and an inability to see their usefulness. ${ }^{3}$ This puts faculty in a unique position. Perhaps more so than in any other course, faculty need support in improving students' learning experiences in these classes. In this chapter, we will describe our initiatives to support engaging research methods teaching, one of which is TeachPsychScience.org, an open-access resource to support teaching research methods and statistics.

\section{The Challenge}

When each of us first began teaching research methods and statistics, we experienced the same problem that many new instructors face. How should I structure my classes to make them both engaging and educational? How can I best promote student enthusiasm for the course? Initially, we did what we imagine other instructors do. We spent time reviewing textbooks, adopting ones that we thought students would find engaging and illuminating. We then constructed our lectures based on the content covered in each chapter, making sure that students memorized the terminology and mastered key concepts. As we gained experience from teaching these courses multiple times, we started to experience a restlessness in our approach. Importantly, the course was not broken or going terribly. In fact, the course was going well. Yes, students were learning. Yes, students gave us favorable course evaluations. However, they were not displaying the same passion for psychological science as we have.

After numerous conversations with our colleagues and soul searching, we began to realize that part of the problem was our approach to teaching. While our students were learning methodological and statistical concepts, they really were not engaging in the process of psychological science. We knew the value of active learning and wanted to include more in our classes, but we had a problem. High-quality teaching demonstrations, activities, and other similar resources to support our teaching of research methods and statistics were extremely limited. There are resources available, but each can be problematic for various reasons.

\section{Instructor Manuals}

One possible place to find these things are the instructor's manuals that accompany methods or statistics textbooks. There are several limitations to relying on instructor manuals. First, the purpose of these manuals is to facilitate the integration of the textbook into one's course, not necessarily improve the overall quality of learning and engagement in the scientific process in that course. 
No text is perfectly comprehensive so there were often topics we include in our classes which are not necessarily covered in the text. Second, the quality of the activities and other materials in instructor manuals is uneven, limiting their utility. If the instructor materials simply reiterate the book's content, it is hard to truly broaden students' exposure to the material and mastery of the skills. Part of the issue may be that the instructor's resource authors tend to be different from the textbook authors and therefore may not be as experienced in teaching the course. The third problem is that even if a textbook has a quality instructor's manual, it is available only to adopters of that textbook.

\section{Teaching Conferences}

Attending national and regional teaching conferences is another way to garner resources. Each of us have gleaned creative teaching demonstrations and strategies from these opportunities. However, few of these conferences focus specifically on teaching methods and statistics. In addition, our limited travel funds meant we had to be judicious in our choices of which conferences to attend.

\section{Teaching Journals}

A third resource are teaching-oriented journals such as the Teaching of Psychology and Scholarship of Teaching and Learning in Psychology. These peer-reviewed journals publish a wide range of articles concerning teaching in psychology. Periodically, a compilation of articles specific to teaching research methods and statistics are published. A recent example is the e-book, Teaching Statistics and Research Methods: Tips from $\mathrm{ToP}^{4}{ }^{4}$ freely available through the Society for the Teaching of Psychology (http://teachpsych.org/ebooks/index.php). These resources are invaluable, but searching opportunities for specific types of activities are limited and they are static in their content.

\section{A Little Piece Project}

In our department, we have an informal motto, 'Take a little piece of your world and improve it.' As we thought about our methods courses, we decided to do more than simply improve the quality of our individual classes. We wanted to take this 'little piece' of our world and improve the quality of instruction in research methods and statistics as widely as possible. We discussed ways for strategies for doing this and the type of support that was available for such open-access initiatives.

We started with a small project, capitalizing on the funding and dissemination opportunities provided by the Society for the Teaching of Psychology (STP). STP has an 'Office of Teaching Resources in Psychology' (OTRP), ${ }^{5}$ dedicated to 
promoting the development of resources for advising and teaching psychology. To facilitate and financially support the development of teaching resources, STP annually offers up to five Instructional Resources Awards. We received one of these awards in 2009 to create a resource for instructors which identifies student-friendly research articles for illustrating various research design elements. We provided instructors with discussion starters and in-class activities to accompany each article. Our goal was to promote the reading of published research studies as students learned about the research process.

We were happy with the result and pleased that we had a means for sharing this open access resource with other instructors via the STP website. ${ }^{6}$ However, we realized we could do more. Given the static nature of a pdf document, our resource was limited in its ability to be efficiently search for specific demonstration ideas. Likewise, we could not continually update this resource as we found new articles employing interesting or creative research designs. Besides, reading actual research studies is just one way in which students can engage in the process of science.

As our conversations continued, we realized that more often than not, when we needed a teaching idea, we would turn to one of our colleagues. We wondered if we could create a centralized repository where colleagues could easily share their ideas, suggestions, and demonstrations specific to teaching research methods and statistics. This website would be dynamic, allowing the posting of new ideas and teaching activities. It would also be easily searchable and provide opportunities for visitor feedback.

Online repositories to support instruction is not a new idea. MERLOT ${ }^{7}$ is a very broad and general repository of resources available to instructors across a wide range of disciplines. As each of us teach social psychology, we can access more than 5,000+ links to teaching ideas and resources on Jon Mueller's 'Resources for the Teaching of Social Psychology' website. ${ }^{8}$ The Social Psychology Network also has a page dedicated to Social Psychology Teaching Resources. ${ }^{9}$ We wanted to create a similar website to specifically support the teaching of research methods and statistics. This open-access website would be textbook agnostic and continually updated with new contributions, minimizing the limitations of instructor manuals. It will provide an ongoing opportunity for instructors to share the ideas, strategies, and activities they use to facilitate student learning in these courses. The idea of TeachPsychScience.org was born.

\section{TeachPsychScience.org}

Creating and maintaining a website is a major undertaking. While one of us had experience with developing a website to support the dissemination of psychological research on relationships to the general public, ${ }^{10}$ we were starting from scratch in the development of this website. We had several guiding principles for our endeavor. First, the resources available on the website had to be 
pedagogically sound. This meant that all submitted material would undergo a peer-review process before being posted on the website. Second, the website had to be user-friendly and searchable, making it easy for instructors to identify resources to meet their immediate teaching needs. Third, the website had to be both sustainable and scalable as we wanted this to become a valuable and ever evolving resource for all methods and statistics instructors.

When we considered issues surrounding copyright concerns, we decide to make all of the resources on the website subject to Creative Commons Licensing. We were not interested in monetizing the website; rather we simply wanted to help others become better teachers of statistics and research methods. We believe that instructors should have a right to modify or adapt the resources to meet their particularly teaching situation. Creative Commons Licensing provides this flexibility while still protecting the author from copyright infringement if the resource is used for something other than noncommercial educational purposes.

As we developed our vision for the website, we knew that finding financial support for this venture would be a major challenge. We are fortunate to have professional organizations in psychology which support pedagogical initiatives. We obtained a grant from the Association for Psychological Science (APS) Fund for Teaching and Public Understanding of Psychological Science. This grant funded the development and maintenance of the website for several years. Second, we needed to find a company to both build and host the site. We had a web designer ${ }^{11}$ work with us to translate our ideas and vision into a viable website. Our goal was to provide a user-friendly website that allowed visitors to find resources in multiple ways, including searching by keywords or category (e.g., experimental designs or factorial analysis of variance). This meant that we had to spend much time planning the organizational structure of the website so that it would be both logical and intuitive to visitors. On the back end, we wanted an administrator interface that we could easy navigate in order to manage and update the content of the website.

Once we created the underlying structure for the website, we needed a core set of resources before we could actually launch TeachPsychScience.org. Drawing upon what we collectively do in our own classes, we created over 50 resources spanning the various categories of resource materials. These resources included class demonstrations, student practice exercises, writing assignments, class/lab activities, and links to other web-based resources supporting the instruction of research methods and statistics. We did not want the site dominated by our own contributions, especially as we wanted to glean ideas from our talented colleagues. We contacted colleagues at other institutions, asking them to submit any activities they used in their methods or statistics classes for inclusion in website. Interestingly, many responded by lamenting that they really did not have any good activities but wished they did. This provided further evidence of the need for the open-access repository we were creating. To expand the resources on the website, we monitored 
teaching of psychology publications and requested submissions from authors. We promoted the website at teaching conferences and teaching workshops and encouraged presenters and attendees to submit any activities or demonstrations they had to the website.

We believe that a key to the success of TeachPsychScience.org is to only include resources that were of high quality. To achieve this, we established a submission and peer-review process to ensure that all materials posted on the website are pedagogically sound. Having added this traditional peer-review process also provided contributors the justification for including their submissions on their curriculum vitae. We contacted scholars in the field of teaching and learning to serve as initial reviewers for the website. We also offered the position to those who contributed several high-quality submissions. To aid the process for reviewers, we created a rating form to accompany reviews and established some basic instructions for reviewers. With the help of between 5-8 reviewers and number of additional submissions, we launched the website on June 1, 2010.

Open-access resources are valuable only if they are known and used. Our first challenge was spreading the word of the site's existence. We contacted other teaching resources sites, asking them to provide a link to TeachPsychScience. org. We advertised the website on various disciplinary websites and at teaching conferences. The site was featured in APA's Psychology Teacher Network Summer 2010 newsletter and is still promoted on APS's website. Over the past four and half years, the site has had over 48,000 users, $66 \%$ of whom were new visitors. Not surprisingly, traffic tends to be higher at the start of the fall and spring semesters. It is clear that this online repository for open-access resources is meeting a need among research methods and statistics instructors.

The second challenge we face is ongoing. The long-term success and value of TeachPsychScience.org depends on the continual submissions of resources by other instructors. Currently, there are over 100 demonstrations and other teaching ideas available for instructors to incorporate into their classes. The continued utility of this open-access resource depends the instructors sharing their creative ideas for promoting student learning in research methods and statistics. Currently, we rotate as editors for the website every 6 to 12 months. One of us takes the lead as the liaison between submissions and reviewers, makes final decision about the quality of a resource, and manages the site content.

Finally, at some point we will need to identify a stable funding source for the continuation of TeachPsychScience.org. Our initial grant provided financial support for the first five years of the website. We recently secured another grant from APS to support the expansion of the website to include resources to support the teaching of scientific writing. As writing is one of the three pillars of the research process, along with statistics and methodology, we felt this missing aspect was critical to develop and share. The additional funding provides support for material solicitation and development, along with a 
redesign of the website. The website update will allow for submissions type we did not originally consider (e.g., submissions that necessitate multiple accompanying files), incorporate writing-specific activities, and make the site more mobile friendly. This additional grant funding will also ensure the availability of the TeachPsychScience.org in supporting quality teaching for the next several years. Eventually, we will need to address the long term viability of the website.

\section{Your Piece of the World}

TeachPsychScience.org started with a simple desire - our wish to improve how research methods and statistics are taught so that all students may come to love the process of psychological science as much as we do. We are fortunate that the financial support we received first from the Society for the Teaching of Psychology and then the Association of Psychological Science, coupled with the Creative Commons License, brought our desire to fruition. It is through the open sharing of our collective wisdom and experiences that we were able to pick our little piece of the world and improve it as we continue to enhance and strengthen learning as students embrace psychological science.

What piece of the world are you going to improve? The fact of the matter is that anyone can replicate our efforts with TeachPsychScience.org in other areas of psychology. Think of the course you teach, your research expertise, as well as the psychology topics that capture your attention. In each of those areas you likely have something valuable to share with your fellow teachers and the field. If you have resources for teaching methods and statistics, we hope that you will share them with us. But more importantly, we hope that you find ways to extend your influence beyond your own classroom, into the classrooms of your colleagues and ultimately to improving students' lives.

\section{Notes}

${ }^{1}$ Rajecki et al., 2005

2 Sizemore \& Lewandowski, 2009.

${ }^{3}$ Sizemore \& Lewandowski, 2009, 2011.

${ }^{4}$ Jackson \& Griggs, 2012.

5 OTRP, n.d.

6 STP, n.d.

MERLOT, n.d.

8 Teaching of Social Psychology, n.d.

9 Social Psychology Teaching Resources, n.d.

${ }^{10}$ Science of Relationships, n.d.

${ }^{11}$ Invisual, n.d. 


\section{References}

Invisual. (n.d.). Available at http://www.invisual.us/

Jackson, S. L., \& Griggs, R. A. (2012). Teaching statistics and research methods: Tips from ToP. Retrieved from the Society for the Teaching of Psychology Web site: http://teachpsych.org/ebooks/stats2012/index.php

MERLOT. (n.d.). Available at http://www.merlot.org

OTRP. (n.d.). Available at http://teachpsych.org/otrp/index.php

Rajecki, D., Appleby, D., Williams, C., Johnson, K., \& Jeschke M. (2005). Statistics can wait: Career plans, activity, and course preferences of American psychology undergraduates. Psychology Learning \& Teaching, 4, 83-89. DOI: https://doi.org/10.2304:plat.2004.4.2.83

Science of Relationships. (n.d.). Available at http://www.scienceofrelationships. com/

Sizemore, O. J., \& Lewandowski, G. W., Jr. (2009). Learning may not equal liking: How a course in research and statistics changes knowledge but not attitudes. Teaching of Psychology, 36, 90-95. DOI: https://doi.org/10.1080/ 00986280902739727

Sizemore, O. J., \& Lewandowski, G. W., Jr. (2011). Lesson learned: Using clinical examples for teaching research methods. Psychology Learning \& Teaching, 10, 25-31. DOI: https://doi.org/10.2304/plat.2011.10.1.25

Social Psychology Teaching Resources. (n.d.). Available at http://www.social psychology.org/teaching.htm

STP. (n.d.). Available at http://teachpsych.org/resources/Documents/otrp/ resources/ciarocco10.pdf

Teaching of Social Psychology. (n.d.). Available at http://jfmueller.faculty. noctrl.edu/crow/ 